\title{
Porous Titanium Scaffolds Produced by Powder Metallurgy for Biomedical Applications
}

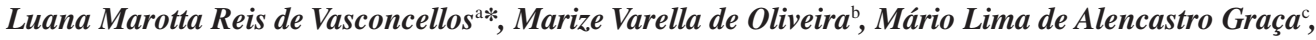 \\ Luis Gustavo Oliveira de Vasconcellos ${ }^{\mathrm{a}}$, Yasmin Rodarte Carvalho ${ }^{\mathrm{a}}$, Carlos Alberto Alves Cairo ${ }^{\mathrm{c}}$ \\ ${ }^{a}$ Department of Bioscience and Buccal Diagnosis, São Jose dos Campos School of Dentistry, \\ State University of São Paulo - UNESP, \\ Av. Engenheiro Francisco José Longo, 777, 12245-000 São José dos Campos - SP, Brazil \\ ${ }^{\mathrm{b}}$ National Institute of Technology, \\ Av. Venezuela, 200, Centro, Rio de Janeiro - RJ, Brazil \\ 'Department of Materials, Air and Space Institute, CTA, \\ Praça Mal. do Ar Eduardo Gomes, 14, 12904-000 São José dos Campos - SP, Brazil
}

Received: January 24, 2008; Revised: August 8, 2008

\begin{abstract}
Porous titanium scaffolds are promising materials for biomedical applications such as prosthetic anchors, fillers and bone reconstruction. This study evaluated the bone/titanium interface of scaffolds with interconnected pores prepared by powder metallurgy, using scanning electron microscopy (SEM) and energy dispersive spectroscopy (EDS). Porous scaffolds and dense samples were implanted in the tibia of rabbits, which were subsequently killed 1, 4, and 8 weeks after surgery. Initial bone neoformation was observed one week after implantation. Bone ingrowth in pores and the $\mathrm{Ca} / \mathrm{P}$ ratio at the interface were remarkably enhanced at 4 and 8 weeks. The results showed that the interconnected pores of the titanium scaffolds promoted bone ingrowth, which increased over time. The powder metallurgy technique thus proved effective in producing porous scaffolds and dense titanium for biomedical applications, allowing for adequate control of pore size and porosity and promoting bone ingrowth.
\end{abstract}

Keywords: biomedical, porosity, osseointegration, titanium

\section{Introduction}

The main goal of tissue engineering is to synthesize or regenerate tissues and organs. Currently, this is achieved by providing a synthetic porous scaffold or matrix that mimics the body's own extracellular matrix, onto which cells attach, multiply, migrate and function. The osteoconductive properties of these porous biomaterials facilitate the migration of osteoblasts from surrounding bone into the implant site, thereby assisting the healing process ${ }^{1}$.

Titanium is widely used for the production of dental or orthopedic implants because direct contact occurs between bones and implant surfaces $^{2}$. Titanium is biocompatible, highly corrosion resistant and durable. Moreover, it is easily prepared in many different shapes and textures without affecting its biocompatibility ${ }^{3}$.

Porous titanium has been used to anchor implants through bone growth into the porous structure ${ }^{4-7}$. This bone ingrowth provides a strong implant/bone bond ${ }^{8-11}$, and the pores may be interconnected threedimensionally to provide enough space for the attachment and proliferation of new bone tissues and to facilitate the transport of body fluids ${ }^{1,12}$. These porous structures have many applications ranging from spinal fixation to acetabular hip prostheses ${ }^{5,13}$, dental implants, permanent osteosynthesis plates ${ }^{13}$, and intervertebral discs ${ }^{5}$. However, there are few techniques for manufacturing these complex shapes with interconnected pores without the need for machining steps ${ }^{1,14-17}$. Several methods have therefore been investigated, including the powder metallurgy technique, which seems to be particularly advantageous because of its processing route and $\operatorname{cost}^{1,14,16-18}$. In powder metallurgy, pores can originate from the particle compacting arrangement or from changes in this arrangement, when decomposition of spacer particles causes increasing porosity, and from solid-state diffusion in the sintering step ${ }^{19}$.
The present study involved an in vivo evaluation of the interface between bone and a novel porous titanium scaffold for biomedical applications, prepared by the powder metallurgy technique, to assess the bone ingrowth, osseointegration and osteoconduction of this biomaterial.

\section{Materials and Methods}

\subsection{Preparation of samples}

Scaffolds of porous titanium and dense titanium were fabricated by the powder metallurgy (PM) technique. The porous scaffolds were made of commercially pure titanium powder produced by the hydrogenation/dehydrogenation technique (HDH) at the Air and Space Institute's Department of Materials (IAE/AMR). The mean grain size of the titanium powder was about $80 \mu \mathrm{m}$, and the urea used as spacer material had a particle size of 250 to $350 \mu \mathrm{m}$. Both the titanium and urea powder presented an irregular morphology. The dense titanium samples were produced only with commercially pure titanium powder.

The porous titanium scaffolds were prepared from a titanium/ urea powder mixture having an 80 -to-20 percent weight ratio. The mixture was uniaxially pressed under $100 \mathrm{MPa}$ in a stainless steel mold and then isostatically pressed under $200 \mathrm{MPa}$. The resulting samples were sintered at $1200^{\circ} \mathrm{C} / 1$ hour under a vacuum $\left(10^{-7}\right.$ torr $)$, and then heat-treated at $180{ }^{\circ} \mathrm{C} / 2$ hours in air to eliminate the spacer particles. The same parameters were used for the preparation of dense titanium samples. 
The sintered samples presented an average diameter of $3.0 \mathrm{~mm}$ and a length of $6.0 \mathrm{~mm}$ (Figure 1). Pore size and distribution in the finished implant were controlled by the size and quantity of urea particles added to the powder titanium.

\subsection{Pore size and distribution - metallographic analysis}

The porous titanium and dense titanium scaffolds were embedded in acrylic resin and sectioned radially with a diamond disc cutter (Labcut 1010-EXTEC). All the specimens were polished lightly using increasingly fine sandpapers $(600,800$ and 1200 grit). After the metallographic preparation, the specimens' pore size, distribution and connectivity were analyzed in a scanning electron microscope (LEO $435 \mathrm{VPI}$ ) with $100 \mathrm{x}$ magnification. The pore percentage and diameter were metallographically analyzed using the Image Tool (Windows ${ }^{\circledR}$ 3.00) software program.

\subsection{Surgical procedure}

Twenty-one New Zealand albino rabbits aged five to seven months, with an average weight of $4.5 \mathrm{~kg}$, were used in this study. The animals, which were supplied by the vivarium of the São Jose dos Campos School of Dentistry, were kept in individual cages and fed with commercial pet food (Coelhil R - Socil, Belo Horizonte, MG, Brazil) and water ad libitum. This study was approved by the Research Ethics Committee, São Jose dos Campos Graduate School of Dentistry - UNESP (044/2002).

Prior to the surgery, the animals were weighed and intramuscularly anesthetized with a mixture of $13 \mathrm{mg} \cdot \mathrm{kg}^{-1}$ of aqueous solution of 2\% hydrochloride of 2-(2,6-xylidine)-5.6-dihydro-4H-1.3-thiazin (Rompum - Bayer ${ }^{\circledR}$, São Paulo, SP, Brazil), an analgesic, sedative and muscular relaxant, and with $33 \mathrm{mg} \cdot \mathrm{kg}^{-1}$ of ketamine (Dopalen ${ }^{\circledR}$ - Agribrands do Brazil Ltda., Paulínia, SP, Brazil), a general anesthetic, at a ratio of 1:0.85. A local anesthetic composed of 3\% oct-

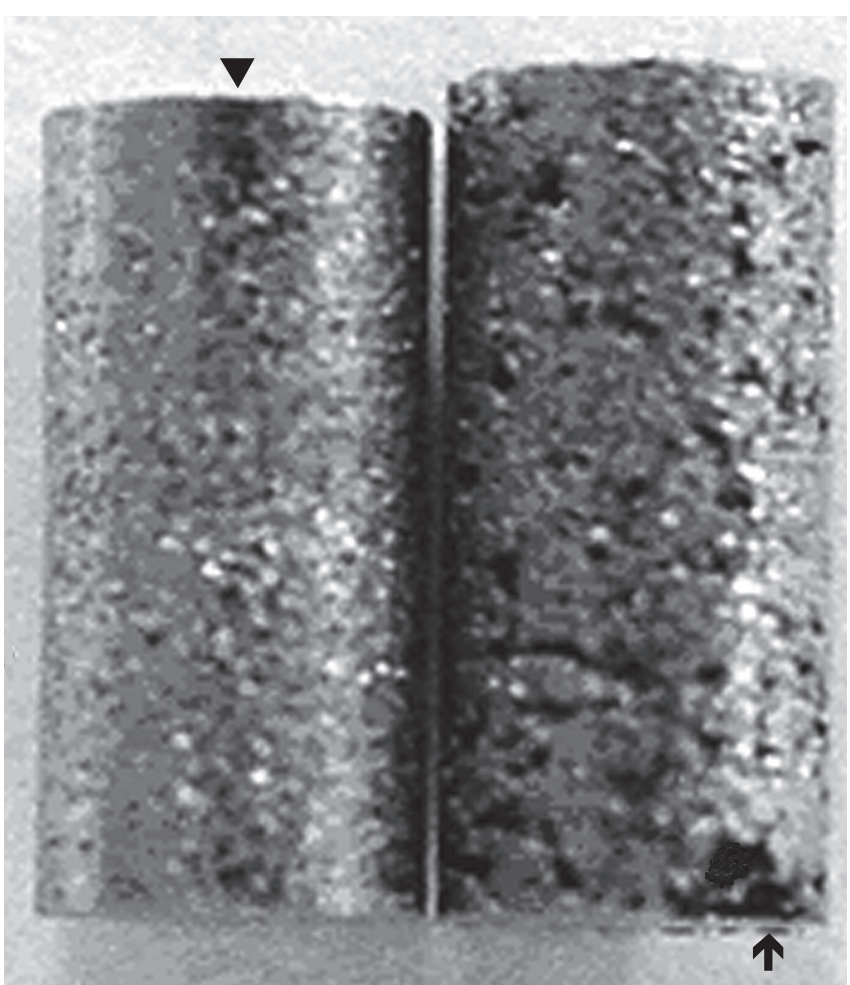

Figure 1. Samples with an average diameter of 3.0 and a $6.0 \mathrm{~mm}$ length. Cylinder of dense titanium $(\checkmark)$; cylinder of porous titanium $(\boldsymbol{K})$. apressin combined with prilocaine hydrochloride and felypressin (3\% Citanest - Dentsply ${ }^{\circledR}$, Petrópolis, RJ, Brazil) was also used.

The procedures were performed under standard sterile conditions. After trichotomy, shaving, and disinfection, a longitudinal incision was made along the medial portion of the tibia. The fascia was split, and the implantation sites were prepared carefully using an electric surgical drill. Three perforations were made bilaterally $0.5 \mathrm{~cm}$ apart. During drilling, the hole was cooled continuously with saline. Immediately before inserting the implants, the hole was irrigated with saline to remove any bone shards.

The specimens, sized to press-fit into such a cavity, were pushed in until they were fixed to the cortical bone. Three porous titanium scaffolds were placed in the left tibia, and three dense titanium samples in the right tibia. The wound was sutured, and all the animals received $0.35 \mathrm{~mL} \cdot \mathrm{kg}^{-1}$ of antibiotic penicillin (Pentabiótico - Fort Dodge ${ }^{\circledR}$ Sacede Animal Ltda, Eurofarma Laboratory, São Paulo, SP, Brazil).

The 21 rabbits were divided randomly into three groups of 7 rabbits each, which were sacrificed 1, 4 and 8 weeks after implantation with an overdose of an intramuscular anesthetic.

\subsection{SEM and EDS analyses}

Following euthanasia, segments of tibia containing the implants were excised and immediately fixed in $10 \%$ formalin, dehydrated and embedded in blocks of polyester resin (Orto Cristal T 208). The blocks were cut serially into longitudinal sections with a diamond disc cutter (Labcut 1010-EXTEC) and polished with progressively fine sandpaper (400, 600 and 1200 grit) in a polisher/grinder (Labpol 8-12, EXTEC). The sections were then examined by scanning electron microscopy (SEM).

The bone-implant interface, preexisting bone, new bone and porous implant were analyzed by EDS at all the ages of sacrifice in order to determine their chemical composition.

\section{Results}

\subsection{Metallographic analysis}

The microstructure of dense titanium samples was devoid of pores. The porous titanium scaffold prepared by powder metallurgy exhibited three-dimensionally interconnected pores, as illustrated in Figure 2. The average pore size was $480 \mu \mathrm{m}( \pm 210 \mu \mathrm{m})$ and total porosity was $36 \%( \pm 2.4 \%)$. The microstructure showed interconnected pores and small isolated pores (Figure 3).

\subsection{Histological evaluation}

All the animals presented satisfactory postoperative results, with no evidence of inflammation or infection in the surgical site. No adverse reaction was observed during the procedure. The appearance of the surrounding tissue and healing in the implantation site were examined, and any mobility of the sample or other abnormalities were noted.

Little or no bone contact was observed a week after implantation, regardless of the type of sample, and minimal bone growth towards the specimen's outer surfaces was observed. However, there was evidence of bone regeneration around the edges of the defect in response to the surgical trauma (Figure 4). During this period, there was a visible gap between the preexisting bone and the sample.

Osseointegration was noted 4 weeks after implantation, with bone ingrowth to porous titanium scaffolds (Figure 5) and bone deposition directly on the surfaces of dense titanium samples (Figure 6). The bone ingrowth invaded the network from the periphery of the implant to the center (Figure 5). In this period, all the samples, regardless of 


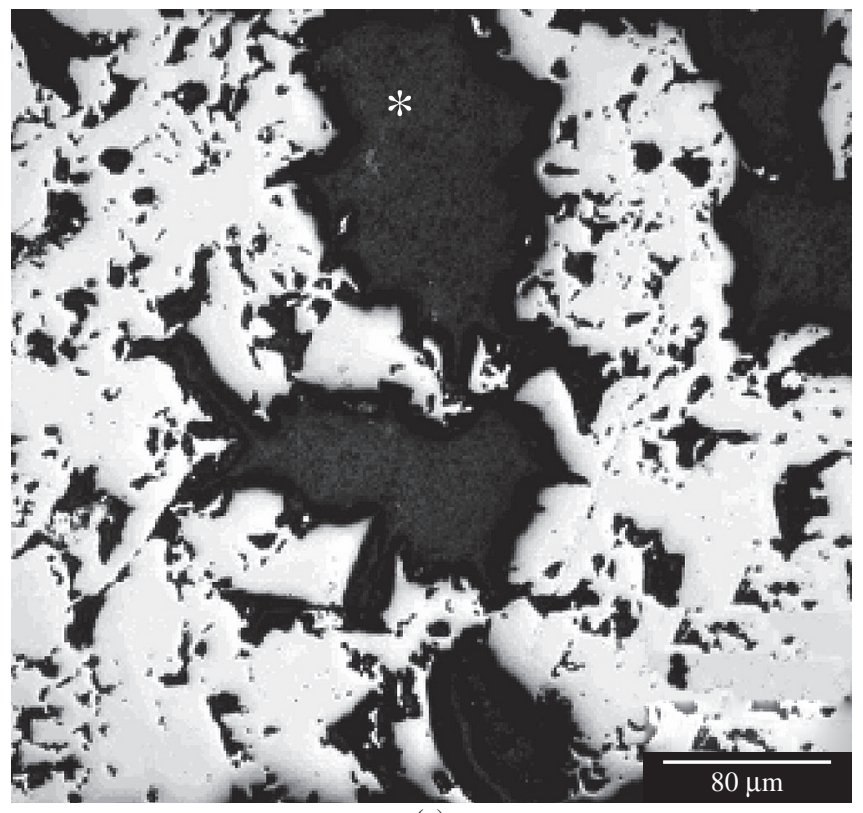

(a)

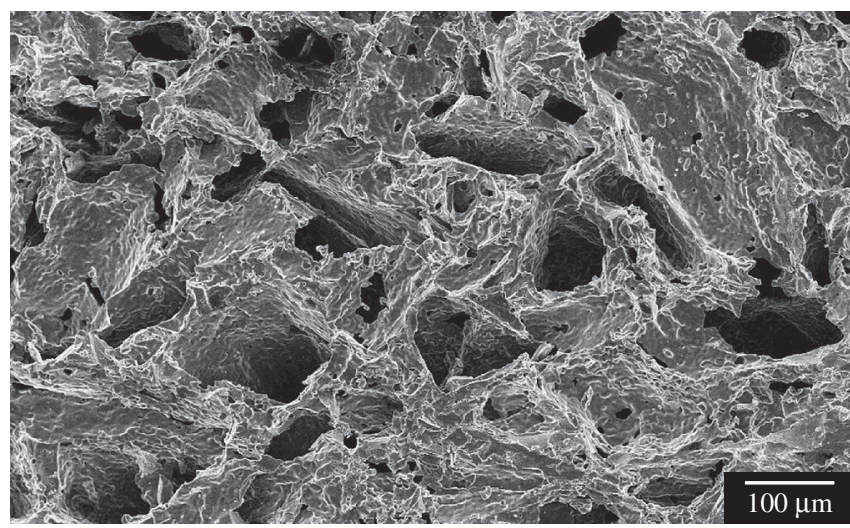

(b)

Figure 2. SEM photomicrograph of a metallographic sample: a) porous structure in the center of the scaffolds, with interconnected pores (*); and b) porous structure in the superficial portion of the scaffolds.

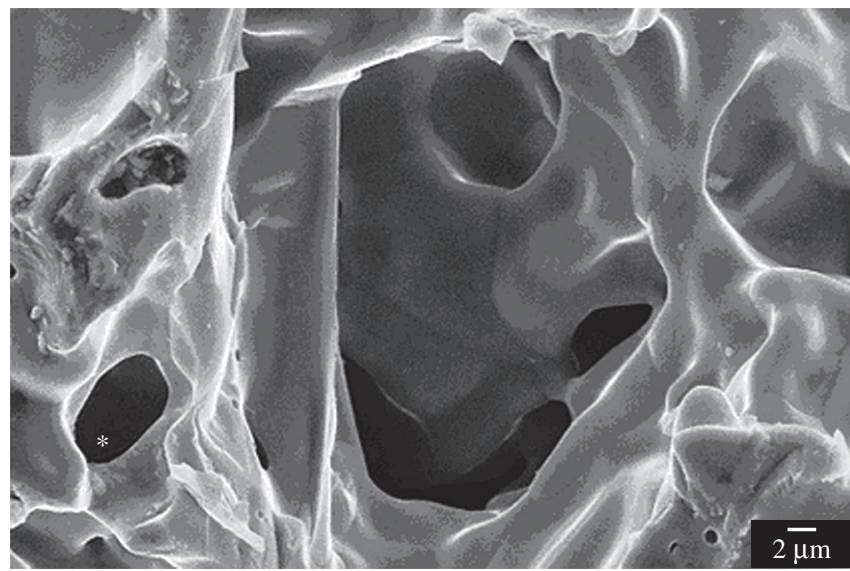

Figure 3. SEM detail of interconnected pores (*).

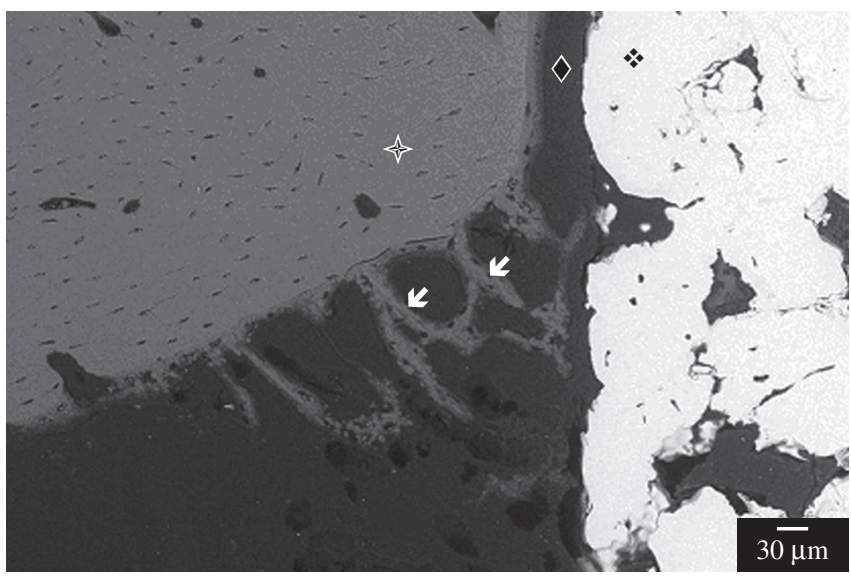

Figure 4. SEM photomicrograph of porous titanium scaffold one week after implantation in rabbit tibia: bone neoformation ( $\mathbf{y})$, gap $(\boldsymbol{)})$ between bone $(\star)$ and implant $(*)$

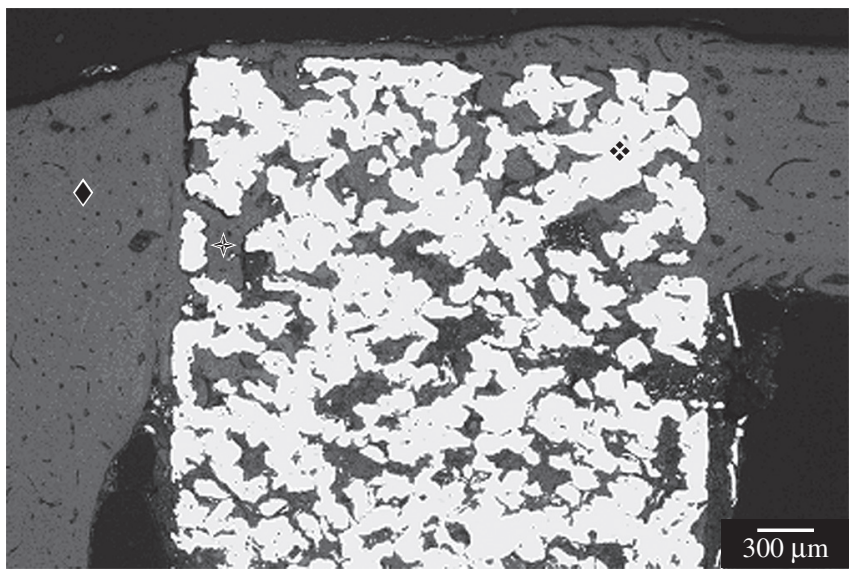

Figure 5. SEM photomicrograph of porous titanium scaffold ( 4 weeks after implantation in rabbit tibia $(\diamond)$, and bone ingrowth $(\uparrow)$.

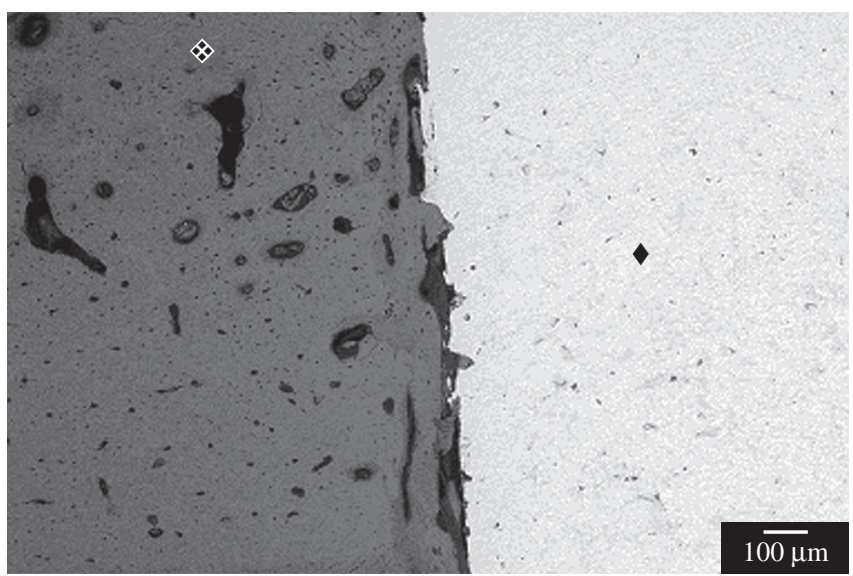

Figure 6. SEM photomicrograph of dense titanium scaffold $(\diamond) 4$ weeks after implantation in rabbit tibia (*). 
their microstructure, displayed woven bone formation with a normal structure and a distinct border between newly formed bone and preexisting bone (Figure 7). In general, smaller pores were filled with bone at four weeks (Figure 7), while larger pores were filled with bone at eight weeks (Figure 8).

Bone tissue deposition displayed a primarily lamellar architecture, with all the samples showing numerous osteocyte lacunae and canaliculi in this new bone eight weeks after implantation. Areas of remodeled bone, characterized by deposition and resorption, occurred within and around all the samples. New bone formation was also observed above the sample, filling the pores in this region (Figure 5), and the bone-implant interface was devoid of fibrous tissue.

\subsection{EDS analysis}

The specimens evaluated a week after implantation showed a gap between the bone and the implant. In this site, the EDS analysis revealed carbon $(\mathrm{C})$ at the bone-implant interface due to infiltration of the polyester resin used in the preparation of the samples. On the other hand, the EDS analysis of the specimens evaluated at four and eight weeks showed calcium $(\mathrm{Ca})$, phosphate $(\mathrm{P})$, and titanium as the main elements at the bone-implant interface (Figure 9). The

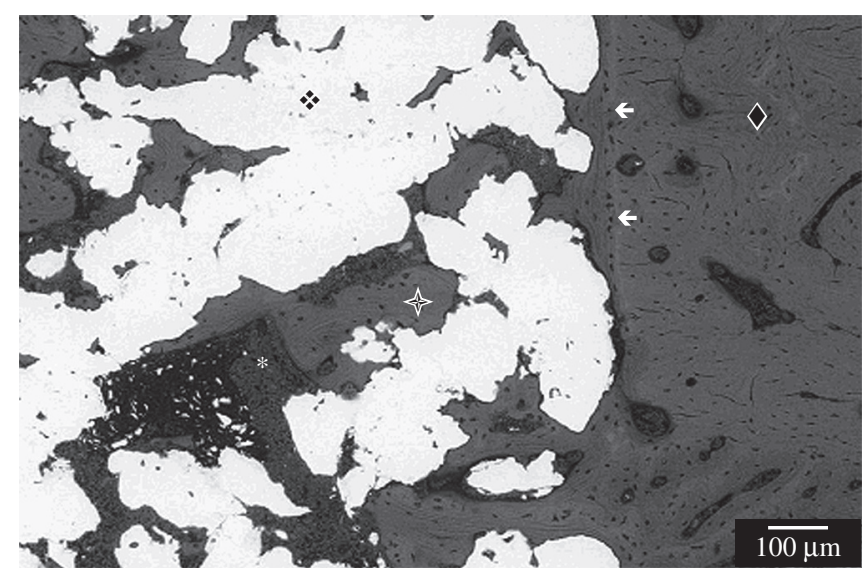

Figure 7. SEM photomicrograph of porous titanium scaffold (*), 4 weeks after implantation in rabbit tibia $(\diamond)$ : distinct border between new and preexisting bone ( $\mathbf{y})$, bone ingrowth $(\star)$, and resin $(*)$.

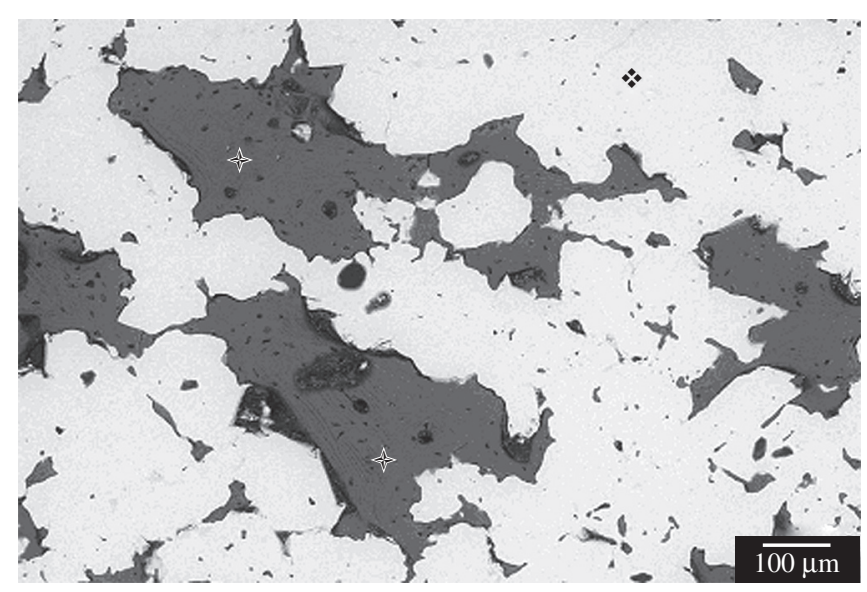

Figure 8. SEM photomicrograph of porous titanium scaffold (*) 8 weeks after implantation: pore filled with bone $(\leftrightarrow)$.
EDS graphic exhibited the energy ( $\mathrm{keV}$ ) corresponding to each element, with $\mathrm{P}$ showing $\mathrm{k}_{\text {alfa }}=2.015$, Ca presenting $\mathrm{k}_{\text {alfa }}=3.69$ and $\mathrm{k}_{\text {beta }}=4.012$, and Ti showing $\mathrm{k}_{\text {alfa }}=4.508$ and $\mathrm{k}_{\text {beta }}=4.931$. Different $\mathrm{Ca}$ and $\mathrm{P}$ intensities were observed in the new bone, and the ratios increased over time.

\section{Discussion}

From a biological standpoint, the ideal material for bone tissue reconstruction is autogenous bone because of its compatibility, osteoinductivity, osteoconductivity, and lack of immunologic response. However, there are limitations to harvesting an adequate amount of autogenous bone, and disadvantages involved in a secondary operation for harvesting autogenous bone. Implant materials, or biomaterials, offer the advantage of being readily available in large quantities, and biomaterial scaffolds are a promising alternative $\mathrm{e}^{1,20}$.

In the present study, we evaluated the in vivo response of rabbit tibia to porous titanium scaffolds and dense titanium samples prepared by powder metallurgy. Our results demonstrated that both titanium devices exhibited osseointegration, with the porous titanium scaffolds presenting bone ingrowth in the pores, which augmented over time. These porous structures show a promising potential as a biomaterial implant system, given their interactions with bone cells.

Bone growth into porous metal depends on several factors, including the porosity of the surface, the stability and degree of micromotion between the implant and bone, whether the host bone is trabecular or cortical, and the presence of gaps between the implant and the bone surface ${ }^{21}$. In the present study, the tight press fit of the implants in the osteotomic cavity was aimed at minimizing gapping and micromotion of the implant.

Osseointegration is strongly affected by the morphology of the porous structure, and the degree of bone ingrowth seems to depend on pore size $\mathrm{e}^{22,23}$. The majority of earlier studies reported porous structures with pore diameters of 100 to $500 \mu \mathrm{m}^{10,11,24-28}$, and a total porosity of approximately $40 \%{ }^{10,11,18,24-27}$. A suitable porous network is required to promote extensive vascularization for bone ingrowth, rapid bone regeneration and good implant integration. Bone ingrowth rates depend to a large extent on pore morphology, the degree of pore connectivity, and pore volume ${ }^{29}$, and it is known that pore connectivity is necessary to enable access of blood and nutrients for bone mineralization $^{22}$. On the other hand, larger pore sizes could weaken the porous implant as a result of an associated reduction in density ${ }^{22}$. The porous titanium scaffold used in this study had a porosity of $36 \%$ and a mean interconnected pore diameter of $480 \mu \mathrm{m}$, allowing nutrients to enter the porous structure and form new bone.

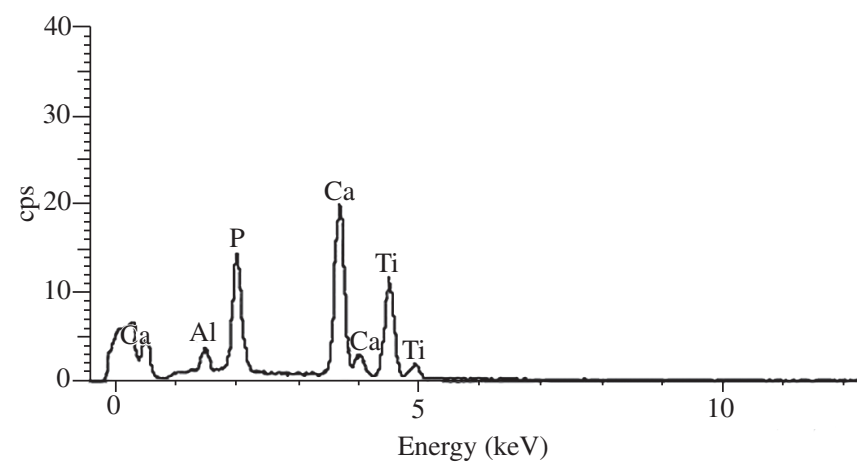

Figure 9. EDS analysis showing main elements of bone-sample interface. 
Earlier results we published about processing of scaffolds and porous coatings indicated that the size and quantity of titanium and spacer powders affect the resulting pore quantity and morphology ${ }^{30,31,32}$. Porous coatings with 11 to $24 \%$ porosity and pore sizes of 56 to $120 \mu \mathrm{m}$ were produced with large titanium particles $(500 \mu \mathrm{m})$ but without using spacer particles. The pore morphology showed mostly closed pores and a few small regions with interconnected pores ${ }^{31}$. In a continuation of this research, coatings and scaffolds were produced from titanium, using urea as spacer, the former with a mean particle size of $160 \mu \mathrm{m}$ and the latter $550 \mu \mathrm{m}$. Spacer quantities varied from 30 to $50 \%$ relative to titanium. The porosities achieved showed complete interconnectivity ranging from 59 to $88 \%{ }^{30}$. The scaffolds obtained in the present work were consistent with and very similar to our earlier results, but we achieved interconnected porosity at a lower level (36\%) by using less spacer $(20 \%)$ and smaller titanium and spacer particle sizes of 80 and $300 \mu \mathrm{m}$, respectively.

Rabbit bone weaves rapidly after injury or biomechanical adaptation, and the lattice of woven bone reaches the implant surface after two weeks. Following this initial period, more orderly deposition of lamellar bone is noted ${ }^{33}$, as was observed in the animals put down four weeks after implantation in this study. Bone was observed at the bone-implant interface and within the pores of the implant remodeling at four and eight weeks. Subsequently, complete penetration of bone tissue occurred even in the innermost pores, thanks to pore interconnectivity.

Several studies of porous biomaterials found that initial bone healing of rabbit tibia began before the end of two weeks, regardless of the use of osteoconductive surfaces ${ }^{22}$, while bone was growing into the pores at four weeks ${ }^{22,23}$, and bone remodeling was concluded at 12 weeks. In the present study, the course of bone healing was similar to previous studies ${ }^{8,22}$, since initial healing was observed at one week, and remodeled bone with a lamellar architecture was noted at four and eight weeks, confirming that the cylinder of porous titanium prepared by PM can be used as a scaffold. No fibrous tissue was found on the bone-implant interface, indicating that this porous titanium scaffold is adequate to promote bone implant contact.

The EDS results showed that the CA/P levels increased over time, which is congruent with the study of Braceras et al. ${ }^{34}$. However, at eight weeks, the $\mathrm{Ca} / \mathrm{P}$ intensities were smaller than that observed in the preexisting bone, suggesting that longer healing times are needed to reach the ideal $\mathrm{Ca} / \mathrm{P}$ rates. The EDS analysis also confirmed the absence of fibrous tissue from the bone-implant interface, since the elements observed here were $\mathrm{Ca}, \mathrm{P}$ and Ti. Lastly, the EDS analysis of the porous titanium implant indicated that the principal element of the commercially pure titanium powder prepared by the hydrogenation/ dehydrogenization technique (HDH) in the Air and Space Institute's Department of Materials at the Air and Space Technical Center (CTA) was titanium, thus characterizing it as biocompatible.

Samples of porous titanium and dense titanium scaffolds were prepared by powder metallurgy, a low cost technique which is economic in terms raw materials. This powder metallurgy technique can be used to produce dense titanium samples without additional materials, or scaffolds of porous titanium with controlled porosity, pore size and morphology, which is ensured through the selection of appropriate spacers $^{1,14,18,27}$. Furthermore, the main advantage of this technique it allows for the preparation of implants with interconnected pores resembling a three-dimensional network ${ }^{17,18,24}$, a feature that was observed in this study. Another important aspect to control during the preparation of a Ti powder metallurgy product is its oxygen content ${ }^{35}$; hence, all the titanium samples were manufactured under vacuum $\left(10^{-7}\right.$ torr $)$.

\section{Conclusions}

Based on the aforementioned results, it can be concluded that the powder metallurgy technique proved efficient in producing po- rous titanium scaffolds and dense titanium samples for biomedical applications. This technique allows for the control of pore size and porosity in porous titanium scaffolds, providing excellent scaffolds for bone ingrowth. In addition, the EDS analysis showed that, after implantation, the $\mathrm{Ca} / \mathrm{P}$ levels improved over time, which constitutes evidence of the mineralization of bone tissue. This type of scaffold can be applied as a graft and an implant for promoting bone ingrowth, and may also serve for the development of new implants for medical applications.

\section{References}

1. Wen CE, Yamada Y, Shimojima K, Chino Y, Asahina T, Mabuchi M. Processing and mechanical properties of autogenous titanium implant materials. J Mater Sci Mater Med. 2002; 13(4):397-401.

2. Branemark PI. Osseointegration and its experimental back-ground. $J$ Prosthet Dent. 1983; 50(3):399-410.

3. Kasemo B, Lausmaa J. Biomaterial and implant surfaces: a surface science approach. Int J Oral Maxillofac Implants. 1998; 3(4):247-259.

4. Torres FG, Nazhat SN, Fadzullah SM, Maquet V, Boccaccini AR. Mechanical properties and bioactivity of porous PLGA/TiO nanoparticlefilled composites for tissue engineering scaffolds. Comp Science and Techn. 2007; 67(6):1139-1147.

5. Likibi F, Assad M, Coillard C, Chabot G, Rivard CH. Bone integration and apposition of porous and non porous metallic orthopaedic biomaterials. Annales de Chirurgie. 2005; 130(4):235-241.

6. Spoerke ED, Murray NG, Li H, Brinson LC, Dunand DC, Stupp SI. A bioactive titanium foam scaffold for bone repair. Acta Biomaterialia. 2005; 1(5):523-533.

7. Kujala S, Ryhänen J, Danilov A, Tuukkanen J. Effect of porosity on the osseointegration and bone ingrowth of a weight-bearing nickel-titanium bone graft substitute. Biomaterials. 2003; 24(25):4691-4697.

8. Story JB, Wagner WR, Gaisser DM, Cook SD, Rust-Dawicki AM. In vivo performance of a modified CSTi dental implant coating. Int J Oral Maxillofac Implants. 1998; 13(6):749-757.

9. Hayashi K, Mashima T, Uenoyama K. The effect of hydroxyapatite coating on bony ingrowth into grooved titanium implants. Biomaterials. 1999; 20(2):111-119.

10. Nishiguchi S, Kato H, Neo M, Oka M, Kim HM, Kokubo T, Nakamura T. Alkali- and heat-treated porous titanium for orthopedic implants. $J$ Biomed Mater Res. 2001; 54(2):198-208.

11. Cook SD, Salkeld SL, Tatron LP, Barrack RL. The effect of demineralized bone matrix gel on bone ingrowth and fixation of porous implants. $J$ Arthroplasty. 2002; 17(4):402-408.

12. Capes JS, Ando HY, Cameron RE. Fabrication of polymeric scaffolds with a controlled distribution of pores. J Mat Sci: Mat in Med. 2005; 16(12):1069-1075.

13. Barrabés M, Sevilla P, Planell JA, Gil FJ. Mechanical properties of nickel-titanium foams for reconstructive orthopaedics. Mater Sci and Engineering C. 2007; 28(1):23-27.

14. Wen, CE, Mabuchi M, Yamada Y, Shimojima K, Chino Y, Asahina T. Processing of biocompatible porous Ti and Mg. Scripta Materialia. 2001; 45(10):1147-1153.

15. Takemoto M, Fujibayashi S, Neo M, Suzuki J, Kokubo T, Nakamura T. Mechanical properties and osteoconductivity of porous bioactive titanium. Biomaterials. 2005; 26(30):6014-6023.

16. Vasconcellos LMR, Momose DR, Brentel AS, Oliveira MV, Carvalho YR, Cairo CAA. Surgical technique to place porous surface dental implants. Acta Microscopic. 2003; 12(suplC): 11.

17. Garcia Barriocanal J, Pérez P, Garcéz G, Adeva P. Microstructure and mechanical properties of $\mathrm{Ni}_{3} \mathrm{Al}$ base alloy reinforced with $\mathrm{Cr}$ particles produced by powder metallurgy. Intermetallics. 2006; 14:456-463.

18. Bram M, Stiller C, Buchkremer PH, Stöver D, Baur H. High-porosity titanium, stainless steel, and superflloy parts. Adv Eng Mater. 2000; 2:196-199. 
19. Ryan G, Pandit A, Apatsidis DP. Fabrication methods of porous metal for use in orthopedic applications. Biomaterials. 2006; 27(12):2651-2670.

20. Bruijn JD, Brink IVD, Mendes S, Dekker R, Bovell YP, Blitterswijk CA. Bone induction by implants coated with cultured osteogenic bone marrow cells. Adv Dent Res. 1999; 13(6):74-81.

21. Cornell CN, Lane JM. Current understanding of osteoconduction in bone regeneration. Clin Orthop. 1998; 1(suppl.355S):267-273.

22. Hing KA, Best SM, Tanner KE, Bonfield W, Revell PA. Quantification on bone ingrowth within bone-derived porous hydroxyapatite implants of varying density. J Mater Sci: Mater Med. 1999; 10(11):663-670.

23. Otsuki B, Takemoto M, Fujibayashi S, Neo M, Kokubo T, Nakamura T. Pore throat size and connectivity determine bone and tissue ingrowth into porous implants: Three-dimensional micro-CT based structural analyses of porous bioactive titanium implants. Biomaterials. 2006; 27(35):5892-5900.

24. Dallant P, Meunier A, Christel P, Guillemin G, Sedel L. Quantitation of bone ingrowth into porous implants submitted to pulsed eletromagnetic fields. In: American Society For Testing Materials. Astm953. Quantitative characterization and performance of porous implants for hard tissue applications. Philadelphia: ASTM, 1987. p. 286-300.

25. Brentel AS, Vasconcellos LMR, Oliveira MV, Vasconcellos LGO, Graça MLA, Cairo CAA, Carvalho YR. Histomorphometric analysis of pure titanium implants with porous surface versus rough surface. Journal of Oral Apllied. 2006; 14(3):213-218.

26. Vasconcellos LMR, Oliveira MV, Graça MLA, Vasconcellos LGO, Brentel AS, Cairo CAA, Carvalho YR. Assessment of influence of implants surfaces and period of repair in answer of in vivo bone tissue. Brazilian Oral Research. 2005; 19:199.

27. Deporter DA, Todescan R, Nardini K. Use of a tapered, porous-surfaced dental implant in combination with osteotomes to restore edentulism in the difficult maxilla. Implant Dent. 1999; 8(3):2333-2340.

28. Bobyn D, Engh CA, Pilliar RM. Histological comparison of biological fixation and bone modeling with canine and human porous-coated hip prostheses. In: American Society for Testing Materials. Astm953. Quantitative charaterization and performance of porous implants for hard tissue applications. Philadelphia: ASTM: 1987. p 185-206.

29. Sepulveda P, Bressiani AH, Bressiani JC, Mesequer L, Koniq Jr. B. In vivo evaluation of hydroxyapatite foams. J Biomed Mater Res. 2002; 62(3):587-592.

30. Oliveira MV, Pereira LC, Cairo CAA. Titanium powder processing with binder addition for medical applications. Materials Science Forum. 2005; 498:173-178.

31. Oliveira MV, Pereira LC, Cairo CAA. Porous structure characterization in titanium coating for surgical implants. Mater Res. 2002; 5(3):269-273.

32. Marcelo TM, Livramento V, Oliveira M. Microstructural characterization and interactions in $\mathrm{Ti}$ - and $\mathrm{TiH} 2$-hydroxyapatite vacuum sintered composites. Mater Res. 2006; 9(1):65-71.

33. Roberts WE. Bone tissue interface. J Dent Educ. 1988; 52(12):804-809.

34. Braceras I, Alava JI, Oñate JI, Brizuela M, Garcia-Luis A, Garagorri N, Viviente JL, Maeztu MA. Improved osseointegration in ion implantationtreated dental implants. Surf Coatings Technol. 2002; 158(9):28-32.

35. Rak ZS, Walter J. Porous titanium foil by tape casting technique. Mater Proc Techn. 2006; 175:358-363. 